\title{
Innovative Solutions for Construction on Problematic Soils in Civil Infrastructure Developments
}

\author{
Mohamed A. Shahin \\ Department of Civil Engineering, Curtin University \\ WA 6845, Perth, Australia \\ M.Shahin@curtin.edu.au
}

\begin{abstract}
Problematic soils pose significant challenges to the geotechnical communities due to their low bearing capacity and high compressibility, causing distress and damage to many civil infrastructure including foundations, retaining walls, pavements, etc. The evergrowing infrastructure developments and their maintenance costs, as well as the expected lifetime of structures and environmental issues have continued to demand unfailing innovation in construction encircling problematic soils. Although the risks associated with problematic soils have been long recognised, problems associated with such weak soils are ever increasing and substantial financial losses have been incurred in many places around the world. Numerous solutions have thus been proposed for problematic soils including replacement of the entire problematic materials, stabilisation by chemical additives (e.g. cement) and the use of pile foundations. However, most existing solutions have either environmental serious concerns (e.g. chemical treatment) or utterly expensive (e.g. pile foundations). In this presentation, two innovative and promising solutions for construction on problematic soils are proposed and their controlling parameters, efficiency and limitations are demonstrated and discussed.
\end{abstract}

Keywords: Problematic soils, ground improvement, bio-cementation, granular pile anchor foundations, numerical modelling.

\section{Introduction}

The ever growing population has led to an increasing demand for new infrastructure developments that are limited by the presence of poor soil conditions. In order to utilise problematic (unstable or weak) soils for infrastructure developments, the soils have to be either improved or replaced with more suitable soil deposits. The goal of soil improvement is to transform the unstable soils, which usually have low bearing capacity and high compressibility, into stable foundations. With roughly 40,000 projects that require soil improvement world-wide each year, adding up to AUD\$6 billion [1], geotechnical engineers are challenged with providing workable ground for most civil engineering structures. The current existing technologies of soil improvement include [2]: chemical stabilisation, strengthening by drainage, densification by mechanical compaction or vibration, pile foundations, reinforcement with steel or geosynthetics and the use of electro-osmosis. Among these methods, chemical stabilisation by grouts is widely employed, where the mineralogical structure of soil is altered by mixing with chemical additives (e.g. cement and lime) to improve the physical and mechanical engineering properties of soils. However, most chemical grouts increase the $\mathrm{pH}$ of groundwater to highly alkaline levels, hinder groundwater flow and significantly reduce soil permeability. More importantly, chemical grouts can cause serious environmental problems and contribute to the ecosystem disturbance. For example, one of the most commonly used chemical grout nowadays (i.e. Portland cement) is a major source of green-house gas emission of global warming, and Li et al. [3] reported that cement production is estimated to account for $7 \%$ of the global carbon dioxide emission. Furthermore, acrylamide grout was associated with five cases of water poisoning in Japan in 1974, resulting in the ban of nearly all chemical grouts [4]. More recently, initiatives in certain countries, such as the USA, have proposed to ban most synthetic grouting materials [1], both because of their toxicity and due to a desire to reduce cement use as this is a major contributor to global anthropogenic carbon dioxide emissions. Therefore, an immense need exists for alternative environmentally-friendly, sustainable and cost-effective technologies that can fulfil the increasing demand for soil improvement.

In this keynote paper, two "innovative" solutions for construction on problematic soils are proposed. Each solution is described in some detail and the corresponding affecting parameters are investigated and discussed. The first solution introduces an emerging biological cementation technique, called bio-cementation, through a process known as microbial induced calcite precipitation (MICP), for stabilisation of loose sand. This technique utilises the metabolic pathway of earthbased bacteria to form calcite precipitation inside the soil matrix, leading to increased soil strength and stiffness while 
maintaining adequate soil permeability. The second solution involves a promising foundation system called granular pile anchor foundation (GPAF) that can be used to mitigate the serious consequences of volumetric changes of reactive clay, both during expansion and shrinkage. The ability of GPAF system to resist the forces induced by the soil movement due to soil moisture variation and impact of this resistance on the superstructure stability, is investigated.

\section{Bio-cementation for Loose Sand}

In this section, an emerging and promising soil stabilisation technique that has recently gained an interest by many researchers and geo-engineers is introduced and presented. The technique is called bio-cementation using microbialinduced calcite precipitation (MICP), which has proved sustainability and capability to alter and improve soil engineering properties. This technology utilises the metabolic pathway of ureolytic bacteria to form calcite precipitation inside the soil matrix, resulting in increased soil strength and stiffness while maintaining adequate permeability. Bio-cementation using MICP usually involves injecting aerobically cultivated ureolytic bacteria, e.g. Bacillus pasteurii (also known as Sporosarcina pasteurii), into soil with the addition of calcium-rich solution and highly active urease enzyme to catalyse the hydrolysis of urea. From this reaction, ammonium and carbonate are produced, and this process can be described as follows [5]:

Urea is hydrolysed by microbial urease to form ammonium and carbonate ions:

$$
\mathrm{CO}(\mathrm{NH} 2) 2+2 \mathrm{H} 2 \mathrm{O} \rightarrow 2 \mathrm{NH} 4++\mathrm{CO} 32-
$$

In the presence of a calcium source (calcium chloride in usually used), the produced carbonate ions react with the calcium ions to produce precipitated calcium carbonate (calcite or $\mathrm{CaCO}_{3}$ ) crystals:

$$
\mathrm{Ca} 2++\mathrm{CO} 32-\rightarrow \mathrm{CaCO} 3
$$

The precipitated calcite bridges the adjacent soil particles together, leading to increased soil strength and stiffness, and forming cemented soil that is very similar to that of calcareous rocks [6]. The rate of calcite precipitation can be governed by many factors such as the amount of $\mathrm{pH}$, concentration of calcium ions and presence of nucleation sites in the soil matrix [7]. MICP simulates the natural digenesis from sand to sandstone, only within a short time instead of million years.

In this section, some results from the work done by the author and his co-workers on bio-cementation are presented, and the practicality of using MICP towards its usage for ground improvement is discussed. The effects of some parameters on biocementation are examined, including the degree of saturation of treated soils, degree of temperature at which bio-cementation occurs, presence of fines in the soil matrix and attainment of treatment uniformity. The possibility of using the seawater as a calcium source for bio-cementation is also investigated, which can significantly reduce the cost of bio-cementation treatment in marine environment.

\subsection{Preparation of Materials}

Industrial pure silica sand, which has the grain size distribution shown in Figure 1, was used for the experimental programme carried out in this study. The sand used was classified as poorly graded (SP) according to the Unified Soil Classification System (USCS) with a predominant particle size of $0.425 \mathrm{~mm}$. This sand was used as it exhibits undesirable engineering properties for most geotechnical engineering applications.

Before conducting the geotechnical engineering tests, specimens from the above sand of $50 \mathrm{~mm}$ in dimeter and 150 $\mathrm{mm}$ in height were prepared for bio-cementation treatment. Highly ureolytic bacteria were cultivated aerobically in the laboratory as follows. The urease active strain used was Bacillus sphaericus (DSM 23526, available from DSMZ, Germany). The liquid medium was prepared using $20 \mathrm{gm}$ per litre of yeast extract added to deionised water. The following substances were added to the media: $0.17 \mathrm{M}$ of Ammonium Sulphate and $0.1 \mathrm{mM}$ of Nickel Chloride. The $\mathrm{pH}$ adjustment was made using sodium hydroxide to obtain a basicity of 9.25 . Before inoculation, the growth medium was sterilised by supplying an inoculum of approximately $2-5 \%$ of pure bacteria culture into the medium to initiate microbial growth, then the medium was incubated for an extended period of time. After 24 hours of cultivation at $28^{\circ} \mathrm{C}$, the bacteria culture was collected and stored at $4^{\circ} \mathrm{C}$ prior to use. The optical density $\left(\mathrm{OD}_{600}\right)$ of the culture varied between $0.6-1.0$, and the urease activity was approximately $5 \mathrm{U} / \mathrm{mL}(1 \mathrm{U}=1 \mu \mathrm{mol}$ urea hydrolysed per min). 
Reagent solutions containing a mixture of $1 \mathrm{M}$ calcium chloride $(111 \mathrm{~g} / \mathrm{L})$ and $1 \mathrm{M}$ urea $(60 \mathrm{~g} / \mathrm{L})$ were flushed through the sand specimens at an injection flow rate of $1 \mathrm{~L} /$ hour. Throughout the flushing applications, fully saturated condition (i.e. (i.e. 100\% degree of saturation) was maintained (except for studying the impact of degree of saturation) using a pressurized pressurized vacuum to remove the previously supplied solution, leaving the next solution application as residual. For the seawater experiments that will be described later, the cementation solution was prepared by adding $10 \mathrm{mM}$ urea $(0.6 \mathrm{~g} / \mathrm{L})$ into seawater.

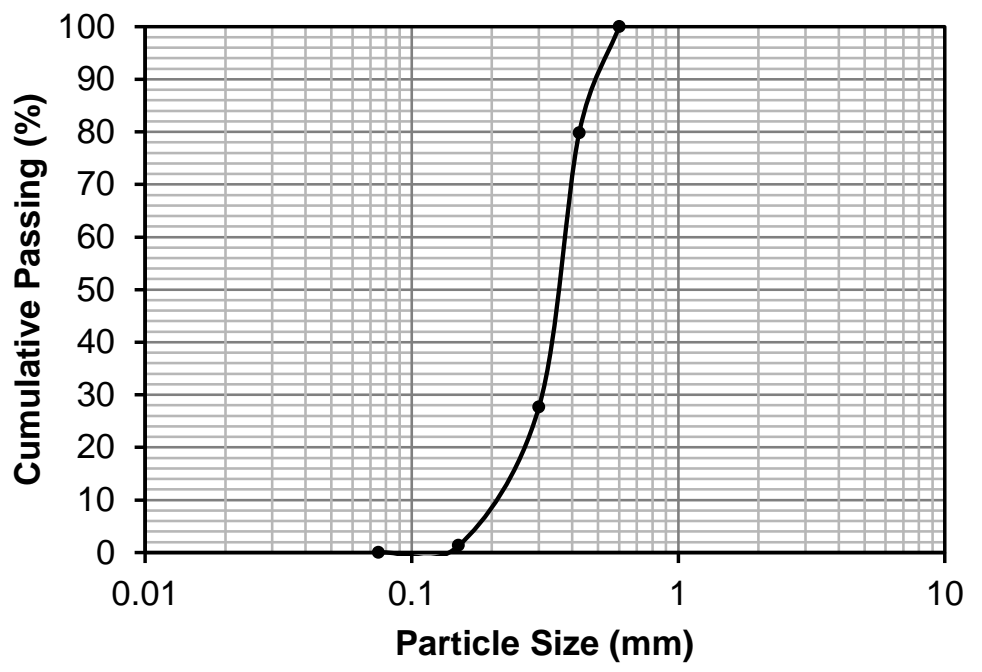

Fig. 1: Particle size distribution curve of sand used in the experimental programme.

\subsection{Degree of Saturation}

The reagent solution (i.e. calcium chloride and urea) was flushed through the sand specimens at various amounts of water, to provide the desired degree of saturation within the soil matrix. Throughout the flushing applications, a specified degree of saturation was maintained using a pressurized vacuum to remove the previously supplied solution, leaving the next solution application as residual. This was achieved using the following three steps [8]: (1) alternating injection of equal volumes of bacterial suspension and cementation solution with an inflow rate of about $1 \mathrm{~L} /$ hour; (2) curing for 12 hours at $25 \pm 1^{\circ} \mathrm{C}$ to allow the bacterial fixation process to complete; and (3) percolation of the cementation solution with the same flow rate followed by another curing period of 12 hours at $25 \pm 1^{\circ} \mathrm{C}$.

Figure 2 shows the UCS results of bio-cemented samples treated at different degrees of saturation of 20\%, 40\%, $80 \%$ and $100 \%$. It can be seen that at any degree of saturation, there is an increase in the soil compressive strength with the increase in the produced calcite content, at any degree of saturation. It can also be seen that at the same calcite content, the soil treated at lower degree of saturation exhibits significantly higher values of shear strength. This can be attributed to the effectiveness of the calcite crystals formation within the soil matrix, which is clearly demonstrated by the images taken from the scanning electron microscopy (SEM) shown in Figure 3 for soil treated at fully and partially saturated conditions. For fully saturated treatment condition (Figure 3a), the produced calcite is not fully formed at the inter-particle contact points of the soil grains but rather floccules either on the grain surface or suspends in the pore space between the soil grains. These nucleation sites are ineffective; hence, the calcite formation provides no significant soil strength improvement. In the case of partially saturated treatment condition (Figure 3b), the calcite formation effectively coats over the soil particles and predominantly occurs at the effective areas of the granular contact points. This calcite formation provides rationale to the significant reduction in the calcite content, obtaining similar strength to that witnessed for the saturated condition. The above results indicate that the mechanical strength of bio-treated soils is gained mainly due to the effectiveness of calcite crystals formation rather than the total amount of produced calcite. Given the verified effectiveness of bio-cementation in increasing the soil strength in a diverse range of in-situ saturation conditions, bio-cementation by MICP may be used as a viable solution to reduce the potential of granular soils to liquefy through providing the soil with greater resistance against the adverse deformations associated with loads induced by earthquakes. It should be noted that the bio-cementation study presented in the remaining part of this paper is focussed only on soil treated at a fully saturation condition. 


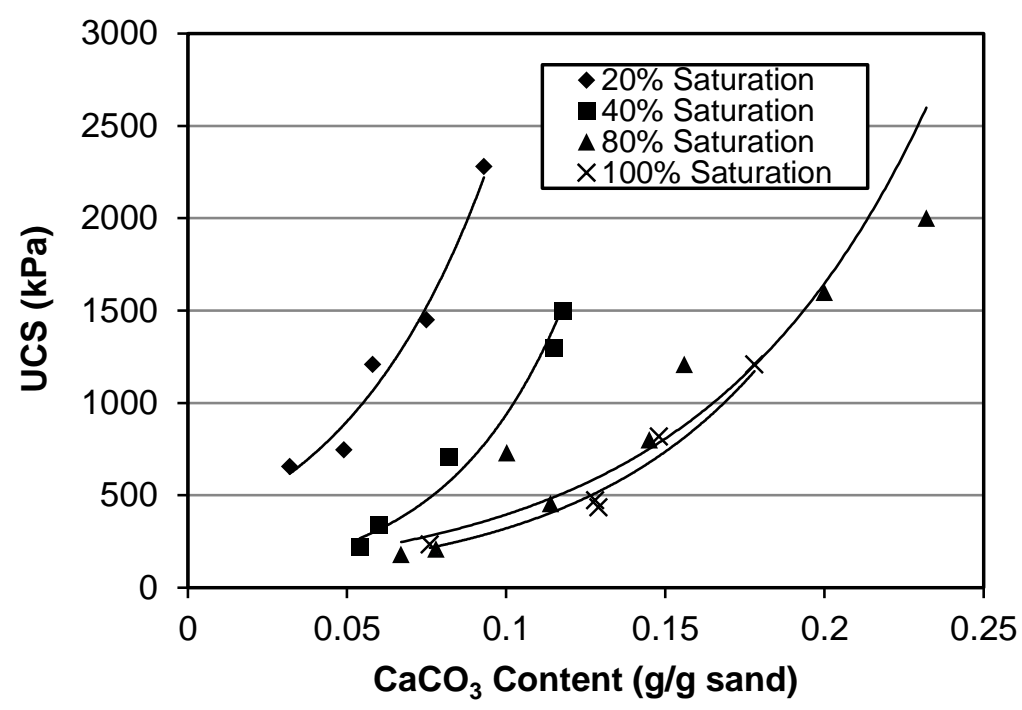

Fig. 2: UCS results of bio-cemented soil at different degrees of saturation [8].
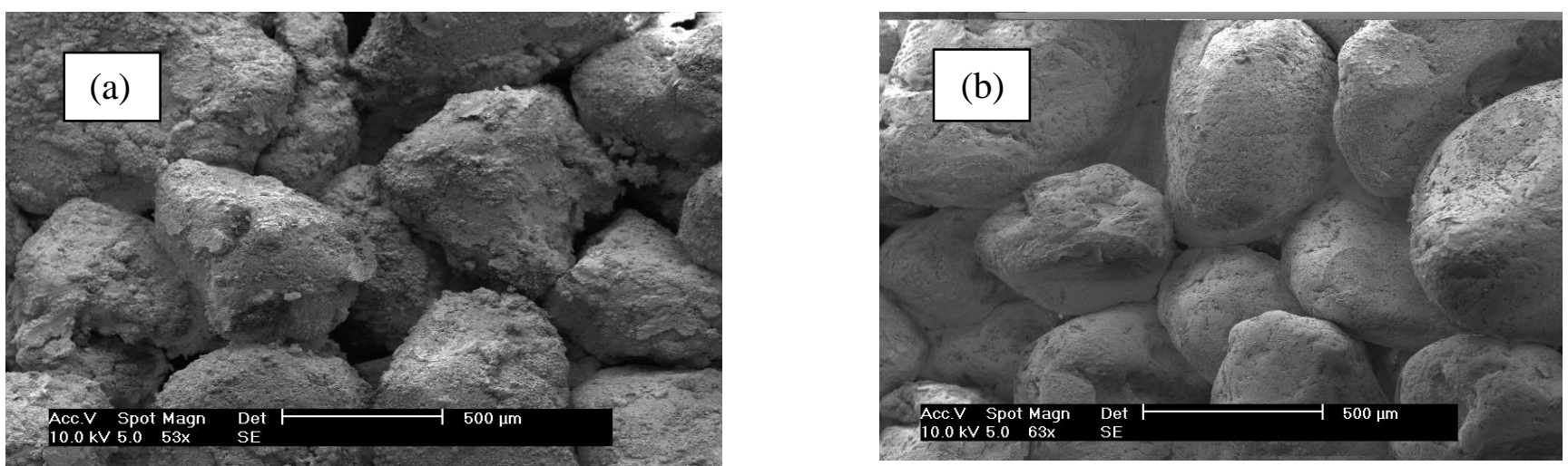

Fig. 3: UCS results of bio-cemented soil treated at different degrees of saturation: (a) soil treated at fully saturated condition; and (b) soil treated at partially saturated condition [8].

\subsection{Degree of Temperature}

It is worthwhile investigating the effect of temperature on MICP cementation as the urease activity of bacteria varies with the change in temperature, leading to different structures of microbially induced crystals. The temperature values used in the current study were selected to simulate the subsurface soil temperature in the cold regions $\left(4^{\circ} \mathrm{C}\right)$, tropical regions $\left(25^{\circ} \mathrm{C}\right)$ and arid regions $\left(50^{\circ} \mathrm{C}\right)$. During the process of MICP treatment, the sand samples used were placed: (1) inside $4^{\circ} \mathrm{C}$ refrigerator; (2) at the room temperature of $25^{\circ} \mathrm{C}$; and (3) inside $50^{\circ} \mathrm{C}$ oven. The UCS tests and SEM analysis were performed for all bio-treated samples.

Figure 4 shows that at any similar produced amount of calcite, the strength improvement is higher at $25^{\circ} \mathrm{C}$ compared to that at either lower temperature of $4^{\circ} \mathrm{C}$ or higher temperature of $50^{\circ} \mathrm{C}$. The calcite crystals formed at $50^{\circ} \mathrm{C}$ were the least efficient to gain strength improvement. The microstructure examination indicated that MICP treatment at $50^{\circ} \mathrm{C}$ results in typical individual small crystals of $2-5 \mu \mathrm{m}$, covering the entire sand grain surface as a coating layer. Small calcite crystals cannot effectively connect the soil grains, resulting in low strength improvement. The formation of such small crystals is probably due to the high temperature at which the rate of calcite nucleation becomes much faster, leading to production of abundant small crystals. For sample treated at $25^{\circ} \mathrm{C}$, it was found that the average crystal size increased by 10 times (individual crystals size between $20-50 \mu \mathrm{m}$ ) compared to those formed at $50^{\circ} \mathrm{C}$. These large calcite crystals were found to precipitate on the grain surface and also cover the contact areas of the sand grains. At low temperature of $4^{\circ} \mathrm{C}$, small individual calcite crystals of 5-10 $\mu \mathrm{m}$ were observed, similar to those observed at $50^{\circ} \mathrm{C}$, and this is due to the slow crystal growth rate as a result of the slow urea hydrolysis process. 


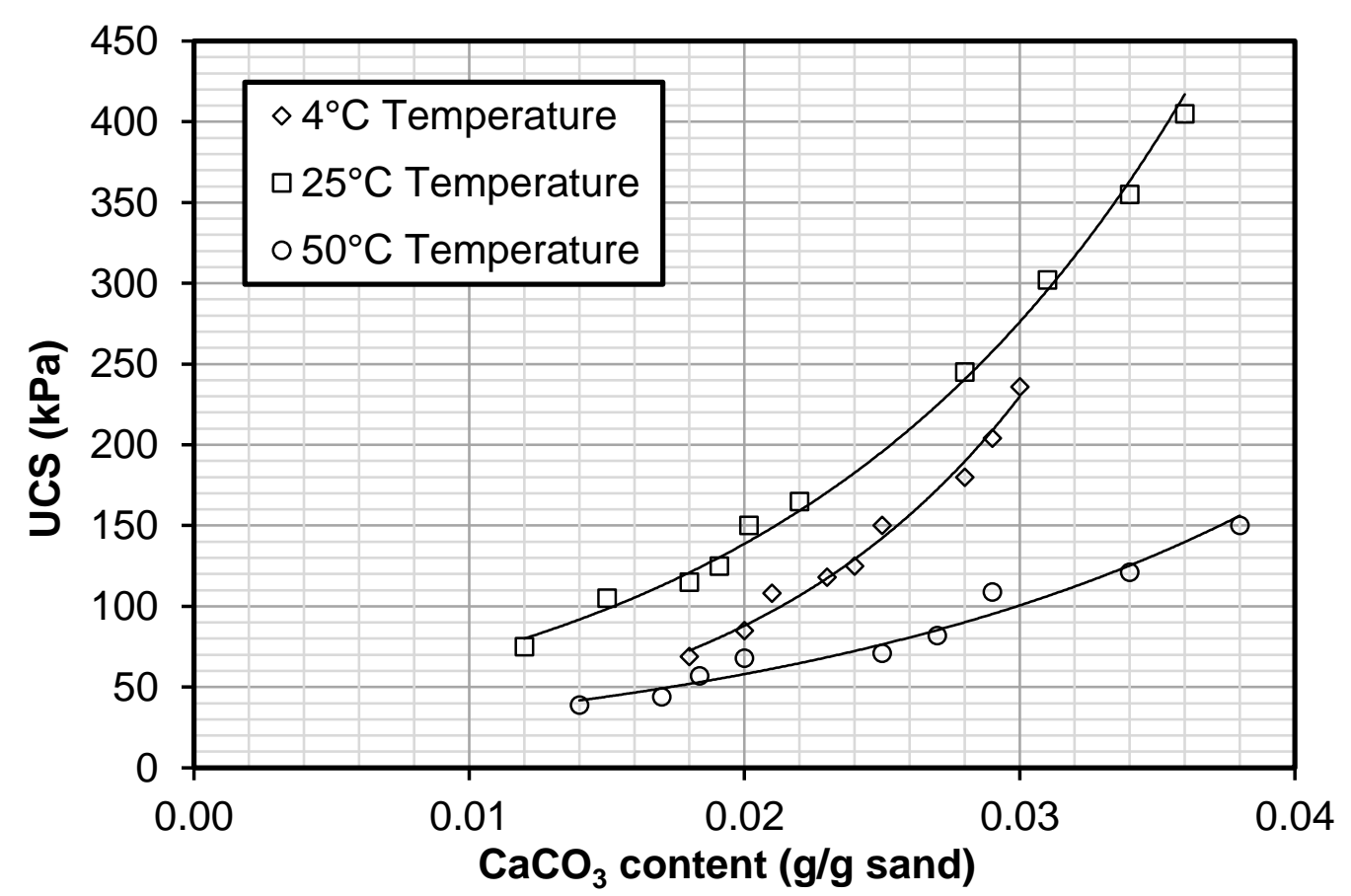

Fig. 4: UCS for soil bio-treated at different degrees of temperature [9].

\subsection{Presence of Fines}

Sand specimens that contain clay fines were treated using the MICP treatment procedure explained earlier and the results are shown in Figure 5. The UCS values of bio-treated sand containing 5\% clay are comparted with those obtained from biotreated pure sand, as shown in Figure 5(a). It can be seen that the UCS increases exponentially with the increase in the calcite content, for both bio-treated sand containing 5\% fines and bio-treated pure sand. However, there is a slight increase in the UCS values of bio-treated sand containing 5\% clay compared to those obtained from bio-treated pure sand. This may be attributed to the increased cohesion of the sand with fines, and it may be also due to the increase in the larger contact surface area provided by the clay fine particles, which may facilitate the bridging formation between the sand particles via the calcite crystals.

In Figure 5(b), the results of bio-treated sand containing 10\% clay fines are shown and indicate clogging by the excessive cementation at the injection end and the minor calcite precipitation inside the treated sand columns. This observation was occurred after three flushes of treatment. Further treatment became difficult to conduct due to the serious clogging. This phenomenon is possibly attributed to the high amount of urea hydrolysed; hence, the calcite formed at the injection end is determined by the presence of urease activity and duration over which the cementation solution is exposed to the clogging area. The sand samples containing $10 \%$ clay content, which have smaller pores, acted as a filter to the bacteria and resulted in accumulation of the bacterial cells (also urease activity) around the injection end. The accumulated urease activity associated with the low infiltration rate of the cementation solution resulted in excessive bio-cementation occurred at the injection end rather than uniformly distributed along the sand columns. This indicates that bio-cementation using the injection method may not be applicable to treat soils that contain more than 5\% fines due to the immediate bio-clogging at the injection end (the bacterial cells block the pores) and thus alternative treatment processes are necessary for MICP treatment of fine-grained soils or coarse-grained soils containing fines. 

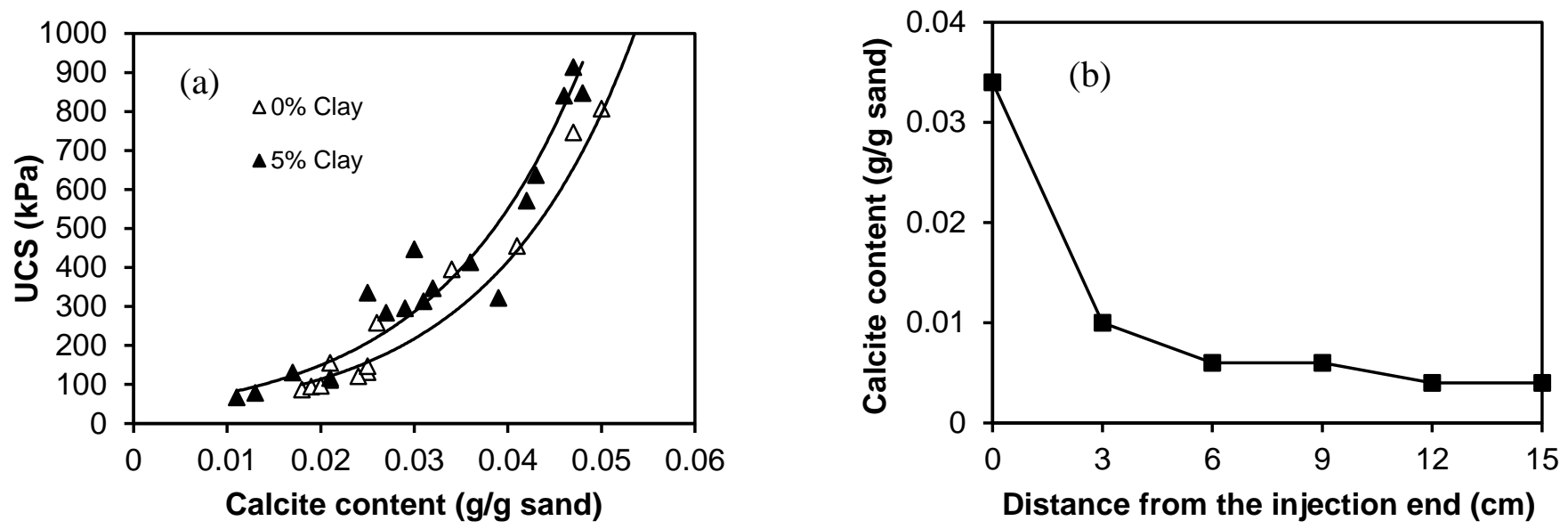

Fig. 5: Impact of adding fines on bio-cementation of sand: (a) calcite content versus UCS for bio-treated sand containing 0\% and 5\% fines; and (b) distribution of calcite content along bio-treated sand column containing 10\% fines [10].

\subsection{Attainment of treatment uniformity}

One of the main intrinsic obstacles of MICP bio-cementation technology as a practical ground improvement methodology is the uniformity of calcite formation and corresponding mechanical strength achieved, which are due to the non-uniform transport and attachment of bacteria to the surface of soil particles. In fact, it is difficult to achieve MICP induced cementation that is highly reproducible and homogeneous. This is because when the bacteria travel through the pore space of soils, they are likely to be filtered through the soil grains with long-linear reduction of microbe concentration along the injection path [11]. Furthermore, the attachment of bacteria to porous materials is usually influenced by many physical, chemical and biological factors, and adsorbed bacteria can be remobilized from the soil surface into the liquid phase by flushing of low salinity solutions [12]. In this paper, a novel approach proposed by the author and his co-workers [13] is presented. The approach uses pre-formed urease active crystals, named as "bio-slurry", as a source of urease activity to induce a homogeneous biocementation for soil stabilisation. In contrast to the current usually adopted MICP treatment methods, the newly invented bio-slurry treatment approach involves premixing of bio-slurry with soil, similar to the traditional cement mixing method, followed by flushing of the cementation solution. Compared to the use of bacterial cells, the advantages of using bio-slurry include more uniform and controllable activity distribution, high urease activity retention and firm attachment against water flushing.

The bio-slurry can be produced from reaction between bacterial culture and $400 \mathrm{mM}$ of $\mathrm{CaCl} 2$ and Urea, forming pre-formed urease active crystals consisting of $\mathrm{CaCO} 3$ plus imbedded urease active bacterial cells (Figure 6). Details description of the bio-slurry preparation is beyond the scope of this paper and can be found elsewhere [13]. By mixing the bio-slurry with sand, more than $95 \%$ of the bio-slurry was retained in the soil matrix as a result of the mechanical trapping mechanism, leading to high resistance to flushing of low salinity solution. The retained urease activity of bioslurry was uniformly distributed along the sand matrix of $300 \mathrm{~mm}$ sand column, resulting in a rather uniform $\mathrm{CaCO} 3$ precipitation (Figure 7). This homogeneous distribution of urease activity is due to the uniform bio-slurry retention. Through repeated treatments with the cementation solution, the unconfined compressive strength of bio-slurry treated sand was significantly improved due to the effective $\mathrm{CaCO} 3$ precipitation at the contact points of soil grains. Scanning electron microscopy analysis carried out on the bio-slurry treated sand revealed that the induced large rhombohedral $\mathrm{CaCO} 3$ crystals were localized around the bio-slurry spherical fine crystals. The overall outcome of this work is that soil biocementation using the new bio-slurry approach is controllable, reproducible and homogeneous. 

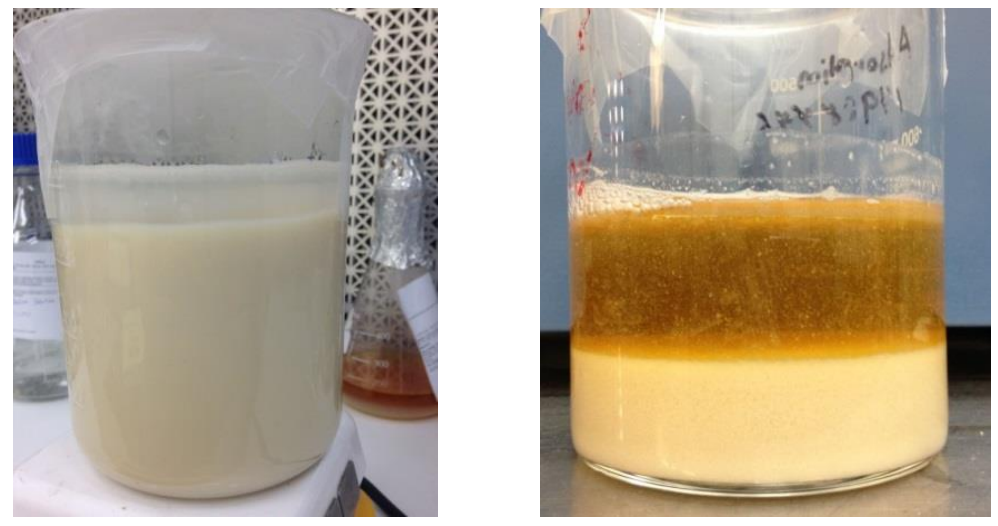

Fig. 6: Photos for the bio-slurry taken during the reaction period (left) and settling period (right) [13].

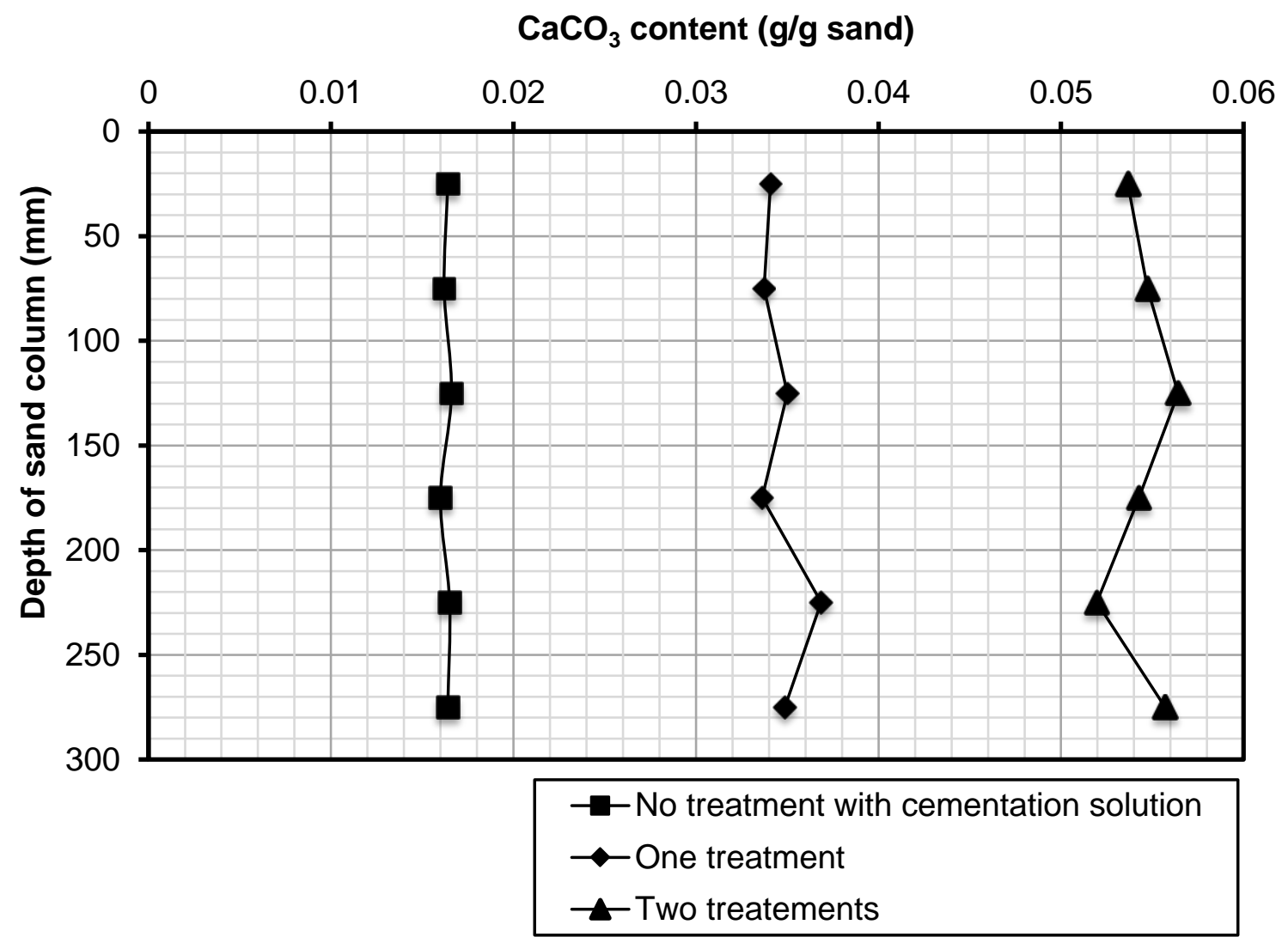

Fig. 7: Distribution of calcite $\left(\mathrm{CaCO}_{3}\right)$ along $300 \mathrm{~mm}$ sand column [13].

\subsection{Use of Seawater as Calcium Source}

The cost of MICP process including bacterial cultivation, chemical usage, equipment and labour may prevent the progress of further commercial development of this emerging ground improvement technique. Consequently, an attempt was made to exploit the potential benefit of using the seawater as a calcium source in the cementation solution instead of the commercially available calcium chloride, to reduce the cost of bio-cementation and bring it closer to be cost-effective and commercially acceptable ground improvement alternative. Some results are shown in Figure 8, which clearly demonstrate the feasibility of using the seawater as a calcium reagent for bio-cementation. It can be seen that the compressive strength of soil is exponentially increased with the increase in the precipitated carbonate content, which is in line with the previous presented results. However, for the same amount of precipitated carbonate, the compressive strength for soil bio-treated with seawater is higher than that of the soil bio-treated using cementation solution of commercial calcium chloride. This is due to the fact 
that higher concentration of urea and commercial calcium chloride usually generates a significant amount of calcite; however, the efficiency of the produced calcite is normally lower compared to that formed at lower concentration produced from the seawater as a calcium resource. However, it should be noted that the use of seawater as a relatively dilute calcium solution requires many subsequent treatment (probably 60 or 80 flushes) to get similar UCS values of those obtained from the traditional cementation solution of urea and calcium chloride; however, each treatment can be completed within a shorter period of time (e.g. 6 hours) compared to 24 hours for a single treatment using the traditional cementation solution.

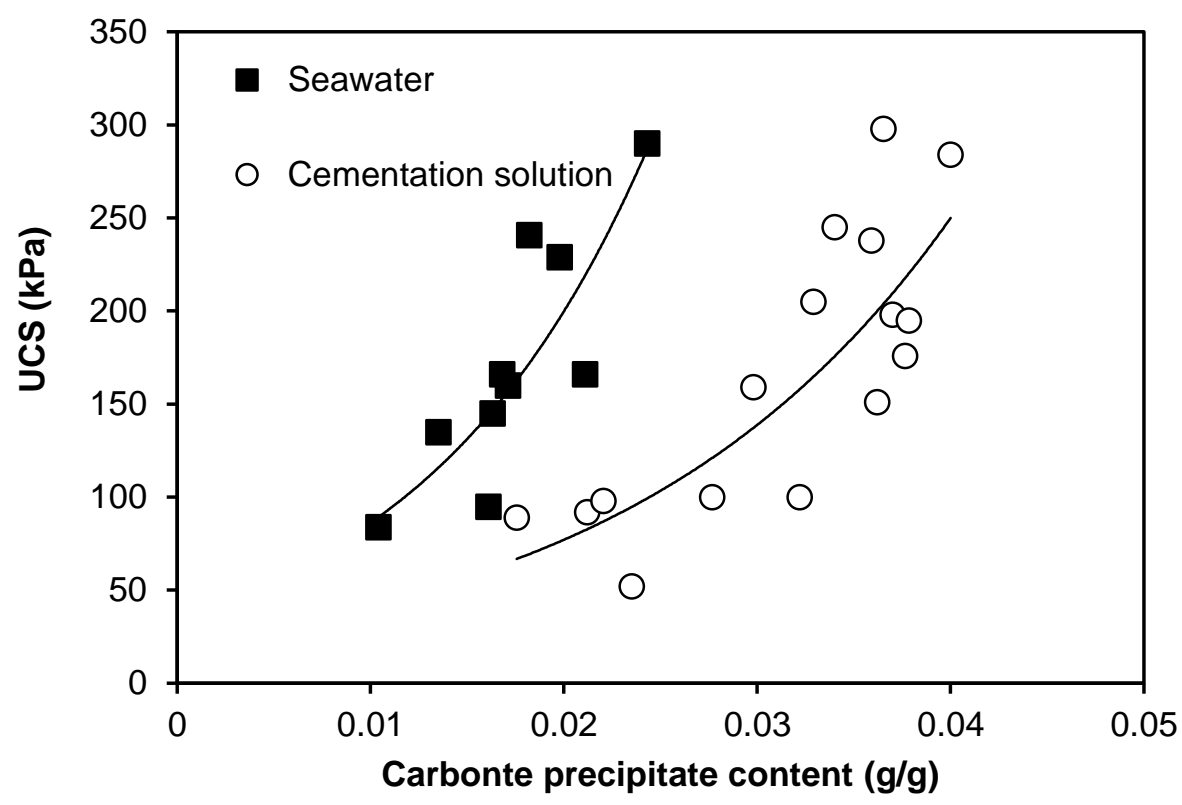

Fig. 8: Bio-cemented soil treated with seawater as the sole source of calcium [14].

\section{Granular Pile Anchor Foundations for Reactive Clay}

Reactive clays swell and shrink with changing moisture content, and pose significant challenges to the geotechnical community due to their potential to cause ground movement, leading to distress to foundations of low-storey buildings and cracking to lightweight structures [15]. Although the risk associated with foundations build on reactive clays have been long recognized, problems associated with such soils are ever increasing. For example, the American Society of Civil Engineers estimated that about one quarter of all homes in the US have experienced some damage from reactive soils; the financial losses incurred by property owners exceed those caused by natural disasters such as earthquakes, floods, hurricanes and tornadoes combined (http://geology.com/articles/reactive-soil.html). On the other hand, despite the stringent regulatory requirements in some countries such as Australia, most lightweight structures built on reactive soils experience some distortional damage during their lives [16].

There are numerous solutions proposed in the literature for construction on reactive soils, including replacement of the entire reactive material, soil stabilisation using a variety of chemical additives (e.g. lime or cement) and the use of pile foundations or drilled/friction piers. One innovative and promising special foundation solution is the granular pileanchor foundation system (GPAF). This foundation system was firstly proposed by Phanikumar and Ramachandra Rao [17] and investigated further by a few researchers during the last decade via laboratory and limited field trials [see 18, 19]. However, the technique has not yet been used in practice primarily due to the ambiguity related to its performance and effectiveness. In an attempt to understand the behaviour of this promising foundation system and its controlling parameters, it was further investigated numerically by the author and his co-workers through the finite element modelling $[20,21]$, and some obtained results are presented below. 


\subsection{Concept of GPAF System}

Figure 9 shows a schematic diagram of a typical GPAF system, which consists of a pile of granular material compacted into a borehole that is made into the reactive soil, and the concrete footing is then constructed above the granular pile. In order to prevent upward movement of the footing during heave of the reactive soil, the footing has to transfer the uplift pressure down to the granular pile via a steel anchor that is casted with the concrete footing. Accordingly, the uplift resistance is ultimately mobilized as shearing stress along the granular pile interface. The force in the pile anchor is transmitted to this interface via a base plate that is rigidly connected to the anchor.

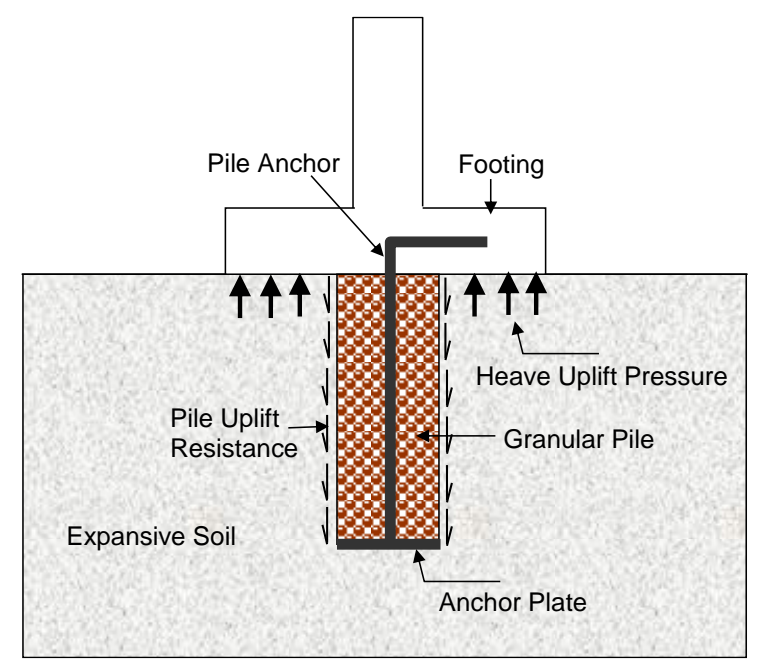

Fig. 9: Schematic diagram of a typical GPAF system [21].

According to the arrangement of the anchorage system of the GPAF, between the footing and granular pile, the latter cannot only reinforce the ground (as in the case of soft clay and loose sand) but can also effectively resist the uplift forces from reactive soils. As can be seen in Figure 9, the uplift resistance of the GPAF system is a function of the self-weight of the pile-footing assembly, interface shear strength, surface area of the granular pile and normal stress developed during the expansion of the soil surrounding the pile.

\subsection{Finite Element Modelling of GPAF System}

The behavior of a single footing reinforced with the GPAF system was investigated using the numerical modelling via the finite element method (FEM) and was analyzed as an axisymmetric problem using PLAXIS 2D software [22]. The 2D axisymmetric model is presented in Figure 10, which consists of 1000, 15 node triangular elements. The footing diameter was fixed at $2.0 \mathrm{~m}$ and the granular pile length was fixed at $3.0 \mathrm{~m}$. The diameter of the granular pile was varied at $0.25,0.5,0.75$ and $1.0 \mathrm{~m}$.

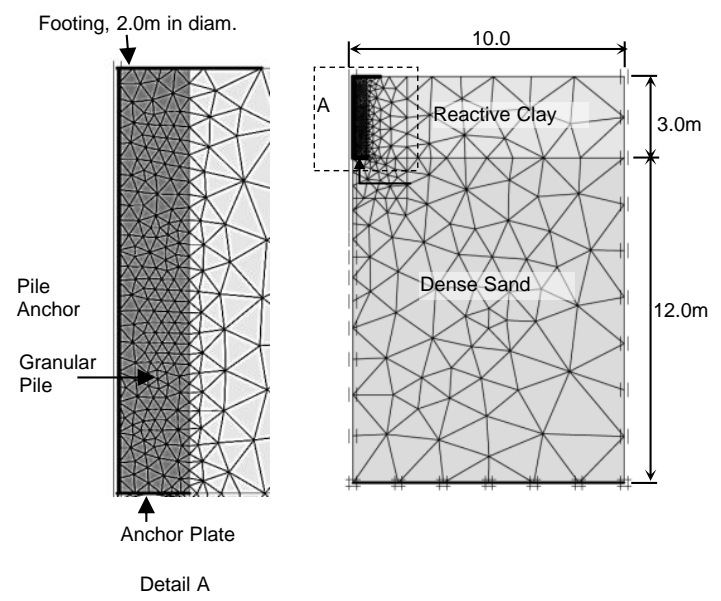

Fig. 10: Finite element model for a typical GPAF system [21].

ICGRE Keynote 2-9 
The idealized ground profile consisted of $3.0 \mathrm{~m}$ of reactive clay overlying dense sand. To improve the accuracy of the analysis, the model was strategically refined around the footing and the granular pile, and to minimize the boundary effect, the pile and boundaries were located farther from the area of interest. The concrete footing was modeled using Mindlin's plate element of an elastic modulus of $35 \mathrm{GPa}$, thickness of $0.6 \mathrm{~m}$ and Poisson's ratio of 0.15 . The pile anchor was modeled as an elastic embedded pile of $30 \mathrm{~mm}$ diameter and Young's modulus of $200 \mathrm{GPa}$. The reactive clay, the underlying dense sand and granular pile material were modeled using the hardening soil model (HS) in PLAXIS [22]. The HS model is a non-linear elastic-plastic formulation which adopts multiple yield loci as a function of plastic shear strain and a cap to allow for volumetric hardening. The non-linear stress strain relationship is represented by a hyperbolic formula, with primary loading governed by a secant deformation modulus $\left(E_{50}\right)$ at $50 \%$ of the material strength. Loading and unloading of the current yield surface are elastic (defined by a separate modulus, $E_{u r}$ ) with failure governed by the Mohr-Coulomb failure criterion. Both $E_{50}$ and $E_{u r}$ evolve with the minor effective stress, $\sigma_{3}^{\prime}$, according to the following formula:

$$
E_{50}=E_{50}^{r e f}\left(\frac{c \cos \varphi-\sigma_{3}^{\prime} \sin \varphi}{c \cos \varphi+p_{r e f} \sin \varphi}\right)^{m}
$$

where; $c$ is the soil cohesion, $\phi$ is the peak friction angle, $m$ is the exponent that controls dependency of the stiffness on stress and $p_{\text {ref }}$ is the reference stress corresponding to $E_{50}^{r e f}$. A summary of the parameters used for all soils are presented in Table 1. The properties of clay were those evolving after the wetting event and during expansion (strictly speaking, the strength of a reactive soil degrades during the expansion but this was not modeled in this study). The clay layer was assumed to behave in an undrained manner during expansion. Heave and shrinkage of the reactive clay were modeled by applying a volumetric strain to the reactive clay layer. In reality, the rate at which the reactive clay would normally expand depends on the location from the source of moisture and magnitude of overburden pressure. However, for simplicity, in the analysis presented herein, the volumetric strain was applied uniformly across the full thickness of the clay layer. In subsequent phase of this work, more realistic FE modelling will be carried out using coupled flowdeformation analysis, which will provide a more realistic soil model that allows the water precipitation and moisture changes, caused by rainfall, to be reliably implemented and simulated.

Table 1: Material properties used in the finite element analyses.

\begin{tabular}{|c|c|c|c|c|c|c|c|c|c|c|}
\hline Soil Layer & $\begin{array}{c}\gamma_{d} \\
\left(\mathrm{kN} / \mathrm{m}^{3}\right)\end{array}$ & $\begin{array}{c}E_{50(\text { ref })} \\
(\mathrm{MPa})\end{array}$ & $\begin{array}{c}E_{\text {oed (ref) }} \\
(\mathrm{MPa})\end{array}$ & $\begin{array}{c}E_{\text {ur (ref) }} \\
(\mathrm{MPa})\end{array}$ & $\begin{array}{c}c \\
(\mathrm{kPa})\end{array}$ & $\begin{array}{c}\phi \\
\left({ }^{\circ}\right)\end{array}$ & $v_{\text {ur }}$ & $\begin{array}{c}p_{(\text {ref })} \\
(\mathrm{kPa})\end{array}$ & $m$ & $K_{0}$ \\
\hline Reactive Clay & 18 & 2 & 2 & 6 & 2 & 24 & 0.2 & 50 & 0.5 & 0.5 \\
\hline Dense Sand (drained) & 20 & 75 & 75 & 200 & 0.1 & 36 & 0.2 & 100 & 0.5 & 0.4 \\
\hline Granular Pile (drained) & 22 & 200 & 200 & 600 & 0.1 & 40 & 0.2 & 100 & 0.5 & 0.4 \\
\hline
\end{tabular}

Note: $\gamma_{d}$ is the soil unit weight; $E_{50(\text { ref })}$ is the deformation modulus at $50 \%$ of strength at reference pressure $p_{(\text {ref })} ; E_{\text {oed }(\text { ref })}$ is the incremental constrained modulus at reference pressure; $E_{u r(r e f)}$ is the unload-reload deformation modulus at reference pressure; $c$ is the soil cohesion; $\phi$ is the soil peak friction angle; $v_{u r}$ is the unload-reload Poisson's ratio; $m$ defines dependency of stiffness on lateral effective stress; $K_{o}$ is the coefficient of earth pressure at rest.

The efficiency of the GPAF system in arresting the deformation of foundations is clearly illustrated in Figure 11, which shows the heave response of the single footing versus the free field heave. As expected, it can be seen that the footing movement is strongly dependent on the pile diameter; the ability of the system to resist various rates of heave seems to improve with increasing the pile diameter. As expected, the load displacement response (Figure 12) of the pile anchor for different diameters of the granular pile indicates that both pile resistance and stiffness increase with increasing pile diameter. However, while the stiffness increases steadily with the pile diameter, the pile size effect on resistance is more dramatic when the pile diameter increases from $0.25 \mathrm{~m}$ to $0.5 \mathrm{~m}$ than from $0.5 \mathrm{~m}$ to $1.0 \mathrm{~m}$. The FE results showed that this cannot be attributed to the resistance component induced by the pile weight; it is rather associated with the failure mechanism which extends outside the pile periphery and engages more soil zones as the diameter increased from $0.25 \mathrm{~m}$ to $0.5 \mathrm{~m}$. 


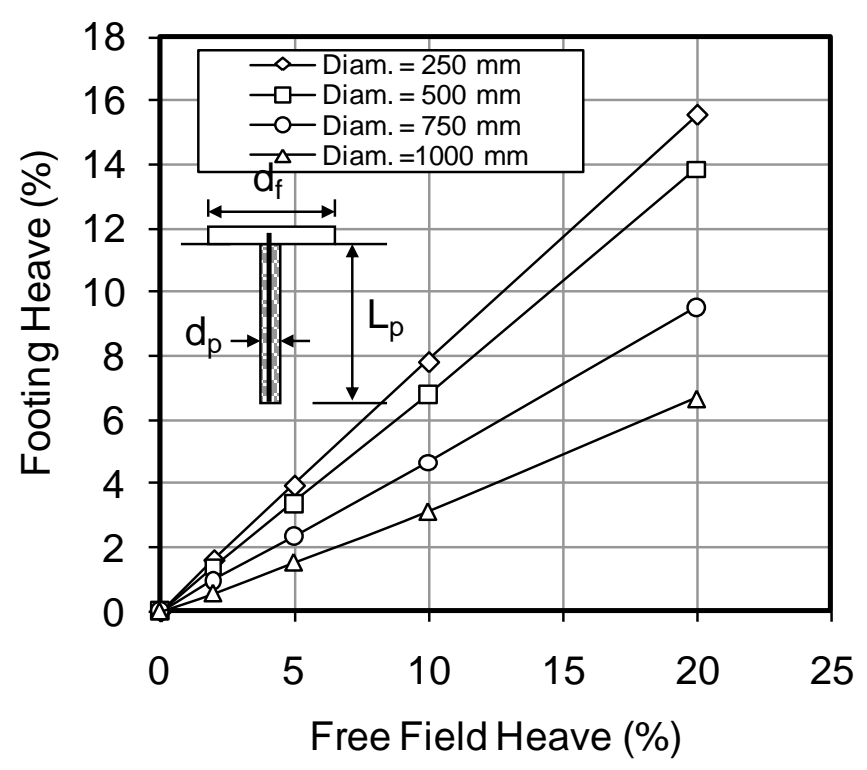

Fig. 11: Heave response of the GPAF system [21].

Figure 12 indicates that establishing the pile resistance response curve is critical in designing the GPAF system for determination of the allowable uplift force that can be resisted by the system and associated allowable heave. For example, it can be inferred that the significant increase in the pile stiffness with increasing the pile diameter could have an adverse effect on the efficiency of the system. The relatively low displacements required to mobilize the full strength of the granular pile system commensurate with the behavior of the conventional, frictional piles that derive their resistance from only skin friction or adhesion. The efficiency of the GPAF system can be expressed in terms of the ratio of the heave experienced by the footing $\left(\Delta H_{\text {footing }}\right)$ to that of the free field $\left(\Delta H_{\text {free }}\right)$, as follows:

$$
\text { Effeciency }(\%)=\frac{\Delta H_{\text {footing }}}{\Delta H_{\text {free }}} \times 100
$$

For a given length of the granular pile, the efficiency depends on ratio of the relative width of the granular pile to the footing width $\left(d_{p} / d_{f}\right)$, where $d_{p}$ is the pile diameter and $d_{f}$ is the footing diameter.

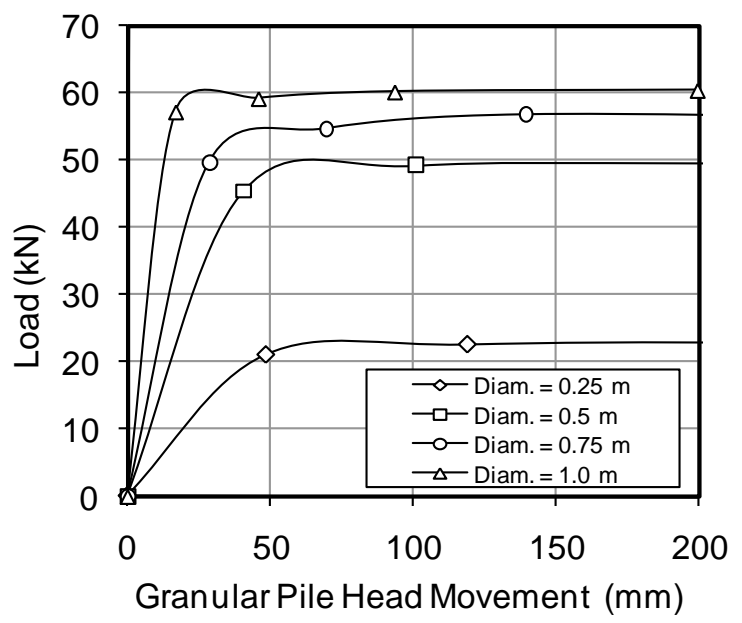

Fig. 12: Load settlement curve of the GPAF system [21].

The influence of the ratio $d_{p} / d_{f}$ is presented in Figure 13 for various heave percentages. It can be observed that the efficiency of the GPAF system increases significantly with the increase in ratio $d_{p} / d_{f}$, and it can also be observed that the 
efficiency of the GPAF system is relatively insensitive to the heave magnitude. It follows from the above discussion that the suitability of the GPAF system depends primarily on the efficiency required to be achieved by the system and the response of the pile load-displacement.

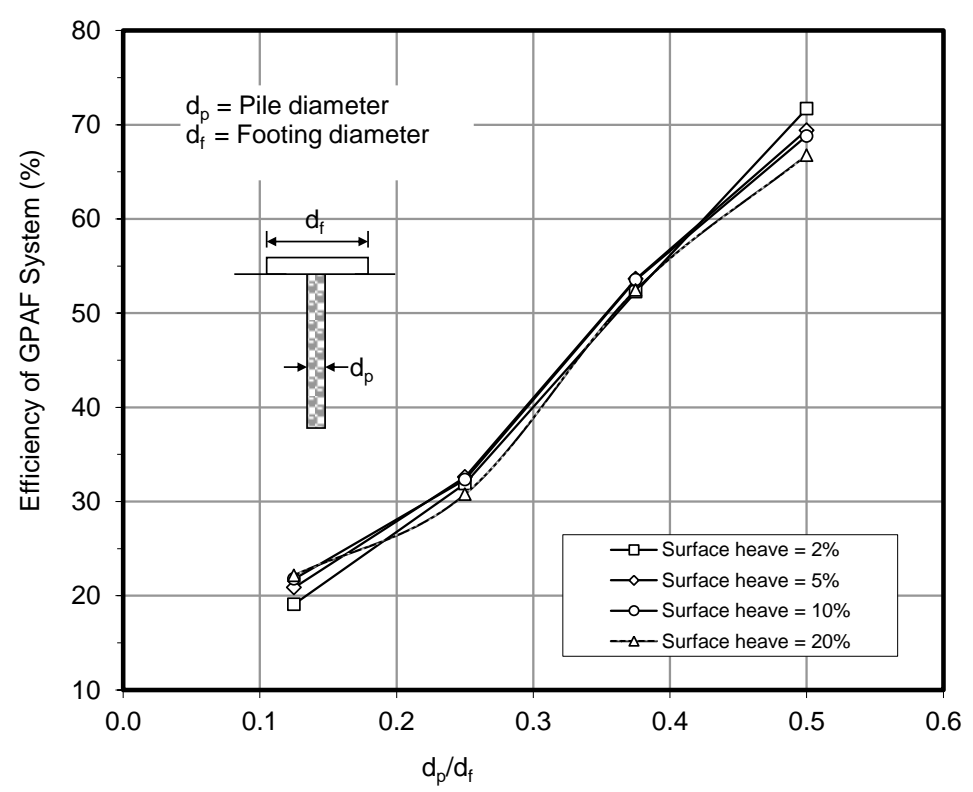

Fig. 13: Influence of footing ratio $\left(d_{p} / d_{f}\right)$ on the efficiency of the GPAF system [21].

\subsection{Analysis of Two-Storey Building on GPAF System}

In order to investigate the efficiency of the GPAF system in practice, a two-story four-bay frame building resting on pad footing with the GPAF system was modelling and analyzed using PLAXIS 3D [23]. An additional independent analysis was also carried out for the same building resting on pad footings without the GPAF and the results were compared with those obtained from the analysis of the building resting on the GPAF system. The two-story building considered was $6 \mathrm{~m}$ high (each story is $3 \mathrm{~m}$ in height), and $20 \mathrm{~m} \times 20 \mathrm{~m}$ in plan with each bay having dimensions of $5 \mathrm{~m} \times 5 \mathrm{~m}$. A ceiling slab of $160 \mathrm{~mm}$ thick was assumed for each story. The slabs are supported by beams, $300 \mathrm{~mm}$ wide and $400 \mathrm{~mm}$ deep, which in turn rest on square columns of dimensions $300 \mathrm{~mm} \times 300 \mathrm{~mm}$. The dead load of each structural component of the frame building was considered according to the material unit weight of that component and an additional distributed live load of $5 \mathrm{kPa}$ was also assumed to act on top of the slabs. All building materials (including footings) were made of concrete of an elastic modulus of $35 \mathrm{GPa}$, Poisson's ratio of 0.2 and unit weight of $24 \mathrm{kN} / \mathrm{m}^{3}$. The GPAF system consisted of square pad footings of dimensions $2 \mathrm{~m} \times 2 \mathrm{~m}$, each supported on a granular pile of $0.5 \mathrm{~m}$ in diameter and $3.0 \mathrm{~m}$ in length. The problem is presented in Figure 14 , which shows the 3D FEM model of the problem with a discretized mesh that consists of 17,880 wedge elements of 15 displacement nodes.

A comparison was made for the top beams (denoted as B1-B4) of the central frame in terms of induced deformations due to heave and shrinkage, as shown in Figure 15, and the angular distortions and bending moments due to heave are given in Table 2. It can be seen from Figure 15 that the ability of the pad footings to resist the vertical movements induced by the soil heave is significantly improved when the GPAF system is used. The maximum vertical displacement induced by the soil heave for the beams considered without the GPAF system was found to be equal to $6.7 \mathrm{~mm}$, whereas negligible vertical movement was developed when the GPFA system is used. More importantly, it can be seen from Table 2 that all beams considered undergo much less angular distortions when the GPFA system is used. For example, the angular distortion of beam B2 without the GPAF system is 300 times greater than that experienced when the GPAF system is used. 


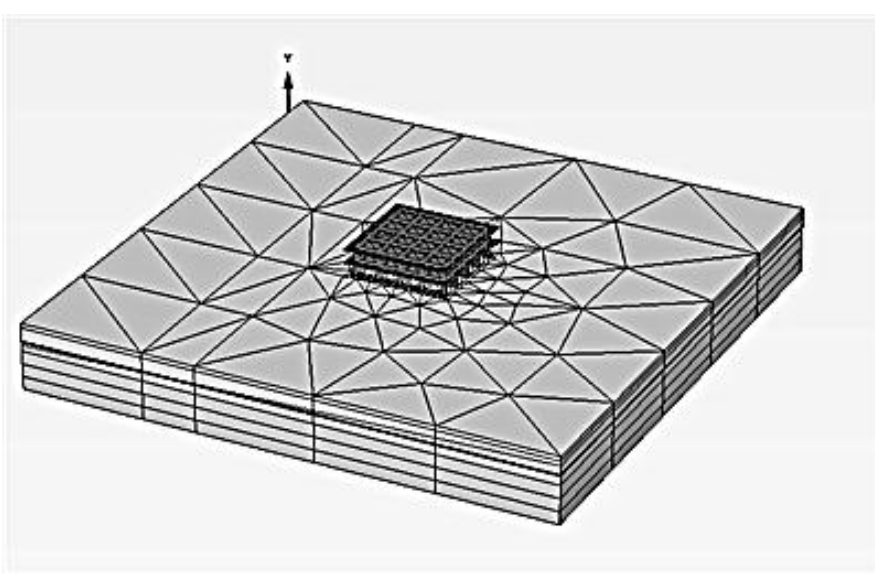

(a)

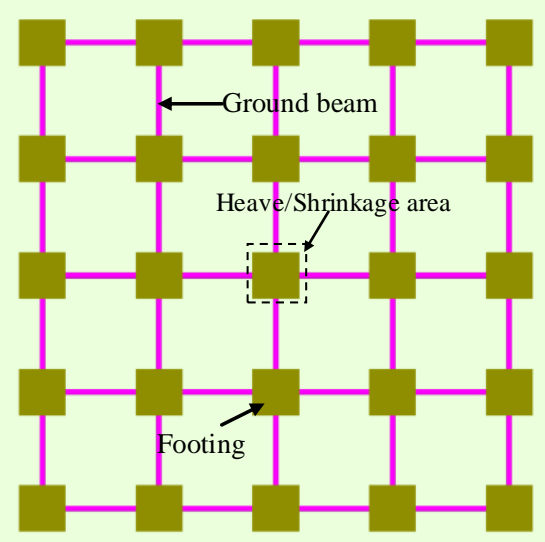

(b)

Fig. 14: FEM 3D model: (a) mesh discretisation of a double-storey frame building constructed on GPAF system; and (b) plan view of building foundation [20].

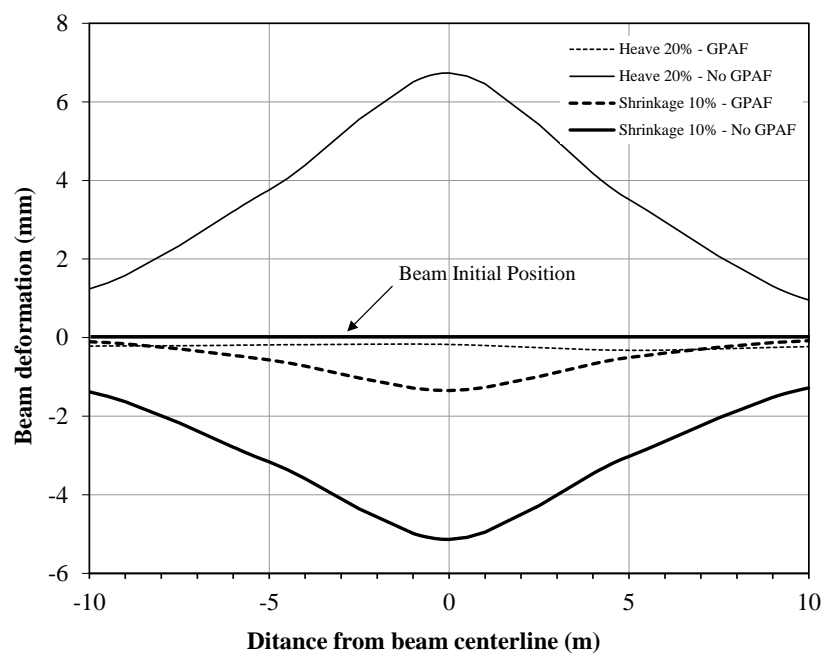

Fig. 15: Deformation of central beams B1 to B4 due to heave and shrinkage [20].

Table 2: Angular distortions and internal forces of building central beams due to heave [20].

\begin{tabular}{|c|l|c|c|c|}
\hline \multicolumn{2}{|c|}{$\begin{array}{c}\text { Beam } \\
\text { Number }\end{array}$} & $\begin{array}{c}\text { Angular distortion } \\
\left(\times 10^{-5}\right)\end{array}$ & $\begin{array}{c}\text { Maximum negative moment } \\
(\mathrm{kN.m})\end{array}$ & $\begin{array}{c}\text { Maximum positive } \\
(\mathrm{kN} . \mathrm{m})\end{array}$ \\
\hline \multirow{2}{*}{ B1 } & GPAF & 0.6 & 44.6 & 23.0 \\
\cline { 2 - 5 } & No GPAF & 50 & 81.2 & 29.3 \\
\hline \multirow{2}{*}{ B2 } & GPAF & 0.2 & 59.8 & 26.0 \\
\cline { 2 - 5 } & No GPAF & 59 & 130.2 & 25.3 \\
\hline \multirow{2}{*}{ B3 } & GPAF & 2.8 & 58.0 & 28.0 \\
\cline { 2 - 5 } & No GPAF & 64 & 132.4 & 28.6 \\
\hline \multirow{2}{*}{ B4 } & GPAF & 1.8 & 44.0 & 25.0 \\
\cline { 2 - 5 } & No GPAF & 51 & 79.7 & 29.6 \\
\hline
\end{tabular}

Note: $20 \%$ Heave: Free field heave $=75 \mathrm{~mm}$

In terms of the suitability of the GPAF system to resist shrinkage when the reactive soil loses moisture, it can be readily shown from Figure 15 that under such an event the GPAF system is capable of arresting the shrinkage and reducing its induced settlement. It was found that the maximum beam settlement induced by soil shrinkage for the building with the GPAF system 
was reduced by $75 \%$ compared to the case of no GPAF system. It should be noted that the capacity of the GPAF system to resist shrinkage is a result of its ability to bear directly on the piles (while still in contact with the shrinking soil), which in turn could engage the bearing capacity of the sand layer that embrace the base plate. Given that the granular pile has no tension or bending capacity, it is therefore expected that the maximum capacity to resist shrinkage will be reached when the shrinking soil detaches itself completely from the granular pile. In such a case the shrinkage resistance can be significantly improved by encasing the granular pile into a stiff, geogrid case to stop the pile from bulging. As can be seen in Table 2, the use of the GPAF system significantly reduced the maximum negative bending moments of all beams, but slightly reduced the maximum positive bending moments. For example, the maximum negative and positive moments of beam B1 are 81.2 and $29.3 \mathrm{kN} . \mathrm{m}$, respectively, for the case without the GPAF system, whereas these values are reduced to 44.6 and $23.0 \mathrm{kN}$.m, respectively, for the case with the GPAF system. The practical implication of these results is that the use of the GPAF system for lightweight structures can significantly reduce the superstructure damage induced by reactive soils, leading to cost savings of structural repairs and ongoing maintenance.

\section{Conclusions}

The results presented for bio-cementation by microbial-induced calcite precipitation (MICP) demonstrated that this promising ground improvement technique can significantly enhance the engineering properties of sand for high compressive strength. However, the efficiency of bio-cementation in improving the soil strength varied significantly according to the physical and environmental treatment conditions. Findings presented in this paper confirmed that higher soil strength can be obtained at lower degree of saturation, challenging the widely belief that bio-cemented soils need to be treated under full saturated conditions. This important finding indicate that optimum performance of soil stabilisation by bio-cementation can be achieved with lower costs, making it economically viable while reducing the need for water, hence more environmentally sustainable than formerly believed. It was also indicated that bio-cementation is able to process in different environmental conditions, such as extreme high temperature. However, the compressive strength of treated soils was found to vary significantly depending on the treatment environmental condition, with lower strength gained at hot temperature of $50^{\circ} \mathrm{C}$ compared to lower temperature of $4^{\circ} \mathrm{C}$ or room temperature of $25^{\circ} \mathrm{C}$. The paper also indicated that bio-cementation of clayey soil or sand with fines is not successful and faces a tremendous challenge; thus, requires further investigation in the future. The paper also emphasised the potential use of the newly proposed bio-slurry approach for MICP soil stabilisation as an efficient alternative approach to the usually used injection method of bacteriacementation solution. The bio-slurry approach was proved to significantly improve the treatment uniformity of the urease activity and calcite precipitation distribution within the soil matrix. It was also shown that it is possible to use the seawater as a chemical reagent for bio-cementation to replace the calcium chloride, and a significant strength improvement can be achieved after repeated treatments. This finding is interesting as it extends the application of bio-cementation to broader areas, such as ground improvement in marine environment. Marine bio-cementation can potentially contribute to more sustainable human activities and significantly benefit society in areas of offshore and onshore infrastructure protection and maintenance, as well as coastline erosion prevention.

The analyses presented for the granular pile anchor foundation (GPAF) system confirmed the potential use of this new technique in resisting the reactive soils for both the heave and shrinkage events. However, the success of the technique in real applications requires reasonable prediction of the load-displacement curve of the pile anchor. The results also showed that one critical limitation of the system may result from the fact that mobilization of the full skin resistance of the pile soil interface requires only small deformation. Further studies are required to explore this limitation whilst considering the working loads applied to foundations. The results also demonstrated the benefit of the GPAF system in reducing the vertical displacement and angular distortion of a light-weight structure induced by soil heave are quite significant, and it was observed that the resistance to shrinkage was improved immensely.

\section{Acknowledgements}

The author gratefully acknowledges the contributions made by several co-workers and colleagues, including Dr Mostafa Ismail and Dr Liang Cheng. The author also thanks his former and current $\mathrm{PhD}$ and undergraduate students who contributed to the experimental programme of the work presented in this paper. 


\section{References}

[1] J. T. DeJong, B. M. Mortensen, B. C. Martinez and D. C. Nelson. "Bio-mediated soil improvement," Ecological Engineering, vol. 36, no. 1, pp. 197-210, 2010.

[2] A. G. Phear and S. J. Harris, "Contributions to Geotechnique 1948-2008: Ground improvement," Geotechnique, vol. 58, no. 5, pp. 399-404, 2008.

[3] J. Li, P. Tharakan, P. Macdonald and X. Liang, "Technological, economic and financial prospects of carbon dioxide capture in the cement industry," Energy Policy, vol. 61, pp. 1377-1387, 2013.

[4] R. H. Karol, Chemical grouting and soil stabilisation. New York: Marcel Dekker, 2003.

[5] S. Stocks-Fischer, J. K. Galinat and S. S. Bang, "Microbial precipitation of CaCO3," Soil Biology and Biochemistry, vol. 31, no. 11, pp.1563-1571, 1999.

[6] J. T. DeJong, M. B. Fritzges and K. Nusslein, "Microbially induced cementation to control sand response to undrained shear," Journal of Geotechnical and Geoenvironmental Engineering, vol. 132, no. 11, pp. 1381-1392, 2006.

[7] A. Al Qabany, K. Soga and C. Santamarina, "Factors Affecting Efficiency of Microbially Induced Calcite Precipitation." Journal of Geotechnical and Geoenvironmental Engineering, vol. 138, no. 8, pp. 992-1001, 2012.

[8] L. Cheng, R. Cord-Ruwisch and M. A. Shahin, "Cementation of sand soil by microbially induced calcite precipitation at various degrees of saturation," Canadian Geotechnical Journal, vol. 50, no. 1, pp. 81-90, 2013.

[9] L. Cheng, M. A. Shahin and D. Mujah, "Influence of key environmental conditions on microbially induced cementation for soil stabilization," Journal of Geotechnical and Geoenvironmental Engineering, doi: 10.1061/(ASCE)GT.9435606.0001586, 2016.

[10] L. Cheng and M. A. Shahin, "Assessment of different treatment methods of micobial-induced calcite precipitation for clayey soil improvement," in Proceedings of the 68 ${ }^{\text {th }}$ Canadian Geotechnical Conference, GeoQuebec. Quebec, Canada: Canadian Geotechnical Society, 2015.

[11] T. R. Ginn, B. D. Wood, K. E. Nelson, T. D. Scheibe, E. M. Murphy, T. P. Clement, "Processes in microbial transport in the natural subsurface," Advances in Water Resources, vol. 25, pp. 1017- 1042, 2002.

[12] M. P. Harkes, L. A. van Passen, J. L. Booster, V. S. Whiffin and M. C. van Loosdrecht, "Fixation and distribution of bacterial activity in sand to induce carbonate precipitation for ground reinforcement," Ecological Engineering, vol. 36, no. 2, pp.112-117, 2010.

[13] L. Cheng and M. A. Shahin, "Urease active bio-slurry: a novel soil improvement approach based on microbially induced calcite precipitation," Canadian Geotechnical Journal, vol. 53, no. 9, pp. 1376-1385, 2016.

[14] L. Cheng and M. A. Shahin, "Cord-Ruwisch R. Bio-cementation of sandy soil using microbial-induced carbonate precipitation (MICP) for marine environments," Geotechnique, vol. 64, no. 12, pp.1010-1013, 2014.

[15] A. Al-Rawas and M. F. A. Goosen, Reactive soils, recent advances in characterization and treatment. London: Taylor \& Francis, 2006.

[16] R. Barthur, M. B. Jaksa and P. W. Mitchell, "Design of residential footings built on expansive soil using probabilistic methods" in Proceedings of the 7th Australia New Zealand Conference on Geomechanics, Adelaide, 1996, pp. 36974.

[17] B. R. Phanikumar and N. Ramachandra Rao, "Increasing pull-out capacity of granular pile anchors in reactive soils using base geosynthetics," Canadian Geotechnical Journal, vol. 37, no. 4, pp. 870-881, 2000.

[18] B. R. Phanikumar, A. Srirama Rao and K. Suresh, "Field behaviour of granular pile-anchors in reactive soils," Ground Improvement, vol. 161, no. G14, pp.199-206, 2008.

[19] R. S. Sharma, B. R. Phanikumar and G. Nagendra, "Compressive load response of granular piles reinforced with geogrids," Canadian Geotechnical Journal, vol. 41, no. 1, pp. 187-92, 2004.

[20] A. Ismail and M. A. Shahin, "Finite element modelling of innovative shallow foundation system for reactive soils," International Journal of GEOMATE, vol. 1, no. 1, pp. 149-55, 2011.

[21] A. Ismail and M. A. Shahin, "Numerical modelling of ground pile-anchor foundations (GPAF) in reactive soils," International Journal of Geotechnical Engineering, vol. 6, no. 2, pp. 149-56, 2012.

[22] PLAXIS 2D Manual, Version 9.0., Delft University of Technology and PLAXIS, The Netherland, 2008.

[23] PLAXIS 3D foundation manual, Version 2.2., Delft University of Technology and PLAXIS, The Netherland, 2008. 